\title{
The Dutch national summit on preconception care: a summary of definitions, evidence and recommendations
}

\author{
Sevilay Temel • Sabine F. van Voorst • Lieke C. de Jong-Potjer • \\ Adja J. M. Waelput • Martina C. Cornel • Sabina Rombout de Weerd • \\ Semiha Denktaș • Eric A. P. Steegers
}

Received: 3 April 2014 / Accepted: 9 October 2014 / Published online: 14 November 2014

(C) Springer-Verlag Berlin Heidelberg 2014

\section{Introduction}

Preconception care (PCC) is widely recognized as a way to optimize women's health through biomedical and behavioural changes prior to conception, ultimately to improve pregnancy outcomes. In terms of prevention, PCC is primary prevention for the future baby and secondary prevention for prospective mothers. When these appropriate secondary and primary preventive measures are taken, public health benefits are achievable by prevention and treatment of identified risk factors (e.g. smoking, alcohol abuse, obesity and infectious diseases) and improvement of perinatal health, potentially leading to improvement of health later in life.

Despite recognition of the importance of PCC in the Netherlands within curative care and governmental policymakers (The Health Council of the Netherlands 2007), PCC is still only delivered on a small scale and not in a uniform manner. Lack of consensus regarding the content and the delivery of the care seems to be an underlying cause. This consensus is important to provide caregivers with a foundation for further implementation of PCC. Consensus is also a necessary first

\footnotetext{
S. Temel $\cdot$ S. F. van Voorst $(\bowtie) \cdot$ L. C. de Jong-Potjer

A. J. M. Waelput $\cdot$ S. Denktaş $\cdot$ E. A. P. Steegers

Department of Obstetrics and Gynaecology, Division of Obstetrics and Prenatal Medicine, Erasmus University Medical Centre, SK 4130, P.O. Box 2040, 3000 CA Rotterdam, The Netherlands

e-mail: s.vanvoorst@erasmusmc.nl

M. C. Cornel

Department of Clinical Genetics, Section of Community Genetics, EMGO Institute for Health and Care Research, VU University Medical Centre, P.O. Box 7057, 1007 MB Amsterdam, The Netherlands

S. R. de Weerd

Department of Obstetrics and Gynaecology, Albert Schweitzer Hospital, P.O. Box 444, 3300 AK Dordrecht, The Netherlands
}

step in creating awareness amongst caregivers regarding their societal responsibilities in primary and secondary preventions.

Therefore, a consensus meeting was organized to identify gaps and essential targets to contribute to policy thinking for implementation of PCC. Point of departure was a comprehensive literature study. This paper summarizes results of the meetings. These results can be used to create commitment and responsibility amongst curative caregivers and public health policymakers to keep the debate going in the content of PCC.

\section{Methods}

A comprehensive literature study was performed to provide a starting point to address five core subjects: (1) the definition of PCC, (2) categories of PCC, (3) relevant target groups and methods for outreach, (4) risk factors which should be taken up in PCC (an evidence update as of 2008) and effective interventions (evidence as of inception of databases) and (5) risk assessment instruments. Despite increasing evidence of paternal influence on pregnancy outcome and the crucial influence of men on their partners' health behaviours, this meeting - and therefore the literature study - firstly focussed on PCC for women. (Frey et al. 2008; Gage et al. 2007; Sternberg and Hubley 2004). This meeting does not have its focus specifically on lifestyle risk factors; however, we would like to point out that we recently have published another systematic review regarding effectiveness of PCC interventions on lifestyle risk factors in the preconception phase (Temel et al. 2014).

The meeting, organized by the Erasmus MC in Rotterdam, consisted of two 1-day sessions (January 2012 and April 2012). Propositions for consensus — based on the literaturewere presented as a starting point for the discussion. 
Participants included

- Caregivers (midwives, general practitioners, gynaecologists, clinical geneticists, an occupational health physician)

- Representatives from professional organizations of the caregivers (regional organisational support [ROS] for primary health care)

- Governmental representatives (the Ministry of Health Welfare and Sport, the Commission for Perinatal Health [College Perinatale Zorg], a Municipal Health Service [GGD Rotterdam-Rijnmond])

- Health insurance companies and the Health Care Insurance Board

- Funders of scientific research (the Netherlands Organisation for Health Research and Development [ZonMW]);

- Providers of health care expertise (the Health Council of the Netherlands [Gezondheidsraad], the National Institute for Public Health and the Environment [RIVM], the Dutch National Genetic Resource and Information Center [Erfocentrum], the Dutch Foundation of Preconception Care [Stichting Preconceptiezorg], Organisation for Applied Scientific Research [TNO], the Dutch birth registry (Netherlands Perinatal Registry [PRN])

- Patient-consumer federation (the Dutch Genetic Alliance of Parent and Patient organizations [VSOP])

- Other relevant disciplines (department of medical ethics, epidemiology).

Sessions were chaired by independent experts on PCC. A consensus was achieved, lack of consensus and knowledge gaps were recorded. These records were verified by participants after each session.

\section{Experts discussion}

Results will be presented per core subject in a fixed format: an introduction, the proposal, achieved consensus (in case of agreement), lack of consensus (if any) and identified knowledge gaps resulting in recommendations for future research.

\section{Definition of PCC}

\section{Introduction}

Various definitions for PCC have been formulated. The definition is an important takeoff point in the debate around the content of PCC. In 1992, the following definition was included in PubMed's MeSH database: "An organized and comprehensive program of health care that identifies and reduces a woman's reproductive risks before conception through risk assessment, health promotion, and interventions" (Pubmed MeSh Database, MeSh term: 'Care, Preconception',
Pubmed database 1992). In 2005, the Centers for Disease Control and Prevention (CDC) and the March of Dimes recognized the need to state that $\mathrm{PCC}$ is a continuum of care throughout the various stages of the reproductive life of women. This was incorporated in their definition: "A set of interventions that aim to identify and modify biomedical, behavioural, and social risks to a woman's health or pregnancy outcome through prevention and management, emphasizing those factors that must be acted on before conception or early in pregnancy to have maximal impact" (Posner et al. 2006). In 2007, the Health Council of the Netherlands presented a definition in line with the CDC: "Preconception care is the entire range of measures designed to promote the health of the expectant mother and her child, which, in order to be effective, must preferably be adopted prior to conception" (The Health Council of the Netherlands 2007).

\section{Proposition}

The proposition is to adapt the definition of the CDC and the March of Dimes due to the different elements of risk factors, defined outcomes and the defined time frame.

\section{Consensus}

- There was agreement with the proposition.

- The following provisions have been added: PCC should be regarded as a programme and that PCC includes psychosocial risks, non-medical risks (e.g. financial problems and domestic violence), counselling and informed decision-making.

- To replace 'woman's health' with 'parental health'.

- To replace 'pregnancy outcome' with 'the health of their future child', prolonging the time frame targeted by PCC.

- A note should be added to the definition about the potential of PCC to reduce perinatal mortality and morbidity.

- The consensus meeting resulted in the following definition: "A set of interventions and/or programmes that aims to identify and enable informed decision-making to modify biomedical, behavioural, and (psycho) social risks to parental health and the health of their future child, through counselling, prevention and management, emphasizing those factors that must be acted on before conception and in early pregnancy, to have maximal impact and/or choice". 1

\section{Knowledge gaps/recommended future research}

- Although major steps are to be made in the implementation of PCC for women first, it is desirable to achieve consensus on PCC for men, in the future.

\footnotetext{
${ }^{1}$ Preconception care may be a good opportunity to reduce perinatal mortality and morbidity.
} 
- Perinatal mortality and morbidity is a more important outcome for policy makers. Therefore, trials should also address pregnancy outcomes (besides behavioural change) as an outcome measure of the effectiveness of PCC (see Fig. 1).

\section{Categories of PCC}

\section{Introduction}

PCC is meant to improve the health of mother and child in various ways. The Dutch Health Council provides the following categorization of methods for PCC delivery (The Health Council of the Netherlands 2007):

- Collective measures are aimed at the general population to improve preconception health. An example is campaigns on the use of folic acid.

- General individual PCC is detection and management or intervention on risk factors in couples planning a pregnancy within the general population. The general nature resides from the fact that these couples mostly do not have a known or predefined preconception risk (profile).

- Specialist individual PCC is provided for (a) couples with a known or predefined risk for an adverse pregnancy outcome (e.g. diabetes) or (b) couples who are referred from general individual PCC after risk assessment (e.g. when diabetes is detected).

Recognition of the different forms of PCC is important in the implementation of PCC. Categorization provides a basis to identify professionals with core responsibilities in a category to tailor a feasible recruitment approach and applicable target group.

\section{Proposition}

- The proposition is not to change the categorization of PCC.

- Care pathways should be formulated for preconception risk factors in respect to the different categories of PCC. They can facilitate implementation of individual PCC in a uniform and locally tailored manner. Care pathways are a means of achieving multidisciplinary agreements on organization and efficient shared care. They should be evidence based and in line with local guidelines and available care facilities (Posthumus et al. 2012).

\section{Consensus}

- Care pathways were recognized to be valuable, specifically where they address socio-medical risk factors. Professional
Fig. 1 Outcomes of PCC. Preconception risk factors potentially and behavioural change may influence foetomaternal health throughout the periconception period, pregnancy as well as during childhood and adulthood. Health during reproductive age will subsequently affect the outcomes of subsequent pregnancies and the health of future generations

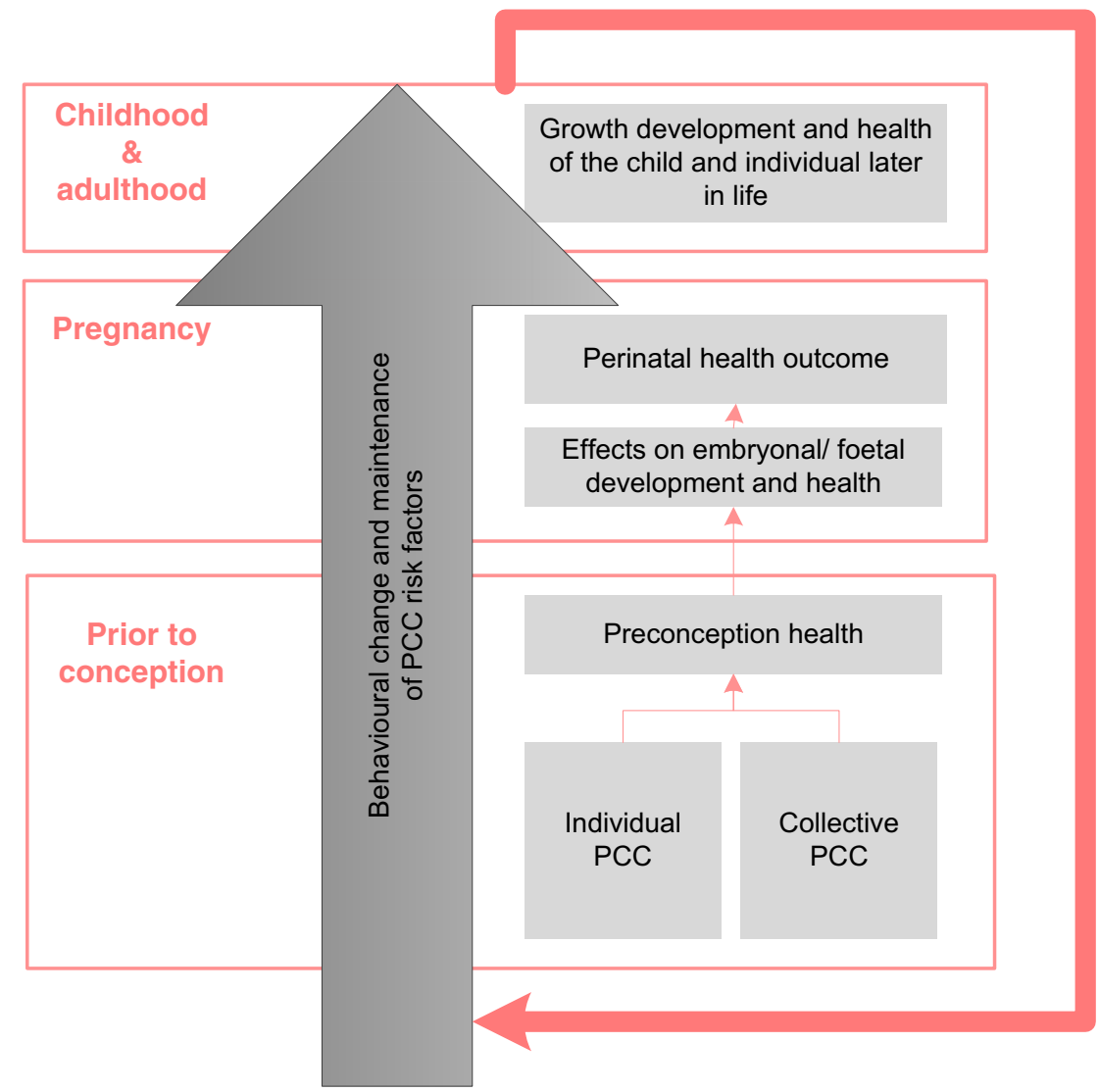


organizations should have a leading role in the development in care pathways, specifically to achieve multidisciplinary agreements.

\section{Disagreement}

- There is unclarity regarding which health care professional has a core responsibility in which category. The line between general individual PCC and specialized PCC is not very evident. There are caregivers that could address both general and specialized individual PCC. The difficulty lays in the education and experience in addressing specialistic risk factors. As PCC has a very broad content, it seems merely impossible for one caregiver to address all risk factors.

\section{Knowledge gaps/recommended future research}

- There is a need to define the role of different professions within the Dutch health care system within different categories of PCC. The collaboration between public and curative health and delegation of tasks (e.g. to qualified physician assistants or nurses) should be explored further. This task can be fulfilled by the Commission for Perinatal Health (CPZ) which has now appointed a committee that will develop a consensus-based multidisciplinary guideline. This guideline will explicate specific roles of health care workers.

\section{Reaching target groups}

\section{Introduction}

So far, no (inter)national consensus exists as to whom PCC should be offered. The target population can be divided into four major groups: (1) the general population, (2) all men and women of reproductive age, (3) men and women aiming to conceive and (4) men and women with predefined high-risk groups (e.g. due to previous pregnancy complications, genetic risks, chronic illness or medication use).

Reaching women and men before the onset of pregnancy is crucial for effective PCC. Women neither actively seek PCC consultation nor do they accept the offer to attend a consultation (Elsinga et al. 2006). In every day practice, clinicians do not often initiate a PCC consultation nor do they recommend it to women (Gaytant et al. 1998; Williams et al. 2006). The curative setting and the public health setting in contact with women of childbearing age should be aware of the importance of preconception health promotion. However, there is a lack of awareness or perhaps sense of responsibility under these professionals about their responsibility and potential role in preconception health promotion.

Research on why the outreach of PCC is limited and how this shortcoming can be addressed is scarce. Several studies have indicated that an important problem with reaching parents to be on time is that many women do not plan pregnancies (Delvoye et al. 2009; van der Zee et al. 2011). Another challenge is adapting the PCC approach to reach specific target groups. The importance is recognized by trials evaluating outreaches of PCC programmes (Denktas et al. 2011; Korenbrot et al. 2002; Owens et al. 2006). Above all, research on effective (tailored) methods to reach target groups for PCC is lacking (Bonsel et al. 2010; Janz et al. 1995).

\section{Proposition}

- Increased awareness and specification of their role in executing PCC should be contemplated by the following caregivers/organizations: governmental organizations, care providers (midwives, general practitioners, paediatricians, gynaecologists and medical specialists in general), youth and family centres, peer educators, social welfare services and schools.

\section{Consensus}

- There was consensus on the fact that preconception health promotion needs broad support from actors with different relations to the target group. The following actors in general were identified additional to the professionals above, either as a direct link to the target population or as a medium: municipal health service, paramedics (e.g. dieticians and dentists), pharmacists, occupational health physicians, all health promotional institutes in general that address people of childbearing age, institutes focusing on migrants, the social network around future parents (e.g. aunts, grandmothers), policymakers and means of communication (e.g. internet). The need for involvement and collaboration of curative health professionals and public health professionals is therefore acknowledged.

- Tailored approaches should be applied by actors for the different target groups of PCC. Specifically, teenagers are a group of interest because early sensitisation could promote timely behavioural change or utilization of PCC services later in life.

\section{Knowledge gaps/recommended future research}

- The consensus meeting concentrated on identifying actors to enlarge awareness and outreach of preconception health 


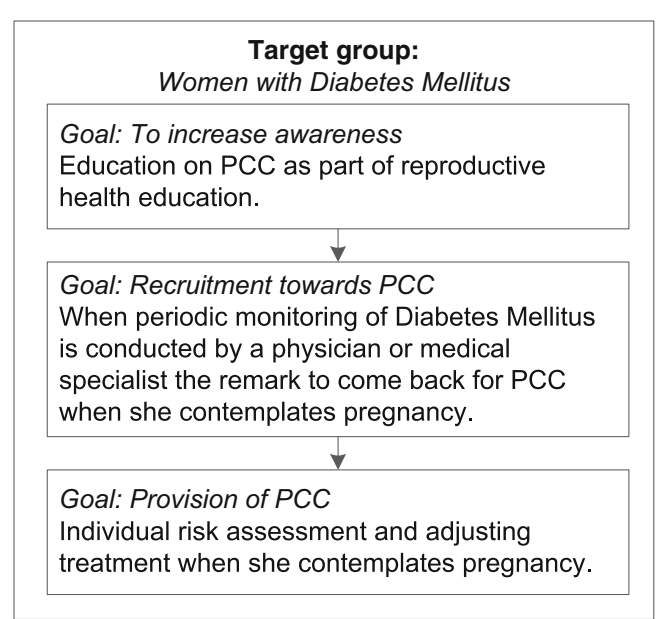

Fig. 2 Target approach to reach women with diabetes mellitus. This figure shows a potential approach to improve preconception health and to target women with diabetes mellitus to utilize preconception care when they contemplate pregnancy later in life

promotion amongst target groups. Feasible approaches should be developed per actor per target group.

- There is a gap in practice as to how the above-mentioned actors optimally could have a role. A potential schematic approach to reach women with diabetes mellitus is shown in Fig. 2.

Risk factors and interventions as part of PCC

\section{Introduction}

For the delivery of PCC, there has to be consensus on the content. This should be based on known risk factors for adverse pregnancy outcomes and effective interventions to address them in the preconception period. A risk factor and intervention review was conducted to form a basis for the discussions.

\section{Risk factors}

A review by Jack et al. was conducted in 2008 to provide evidence for risk factors to be taken up in PCC (Jack et al. 2008). To update this review for the consensus meeting, a search was conducted in PubMed as of 2008. Selection was performed according to predefined criteria: the study assesses risk factor(s) which are present in the preconception period and the study reports an association with an adverse pregnancy outcome. Three reviewers independently assessed eligibility and performed data extraction. The search resulted in 2214 articles of which 178 articles were included.

\section{Interventions}

A systematic search was conducted to assess efficacy of available PCC interventions in PubMed, Embase and Web of Science from 1900 to January 2012. Selection was performed according to predefined criteria: the study assesses interventions, addressed in the preconception phase for an adverse pregnancy outcome. Two reviewers independently assessed eligibility of 678 articles and performed data extraction on 104 included articles.

Table 1 gives an update of the quality of the evidence for the risk factors per domain with interventions where available. Strength of evidence was assessed according to the Canadian Task Force on Preventive Health Care (US Preventive Services Task Force. Guide to clinical preventive services 1996)

\section{Proposition}

- Identified risk factors and available interventions with a level of evidence of I-A to II-3 should be included as part of evidence-based PCC.

- Identified risk factors with a level of evidence of I-A to II3 , but without evidence-based interventions, should be prioritized for the development of interventions.

\section{Consensus}

- Table 1 shows the consensus achieved per risk factor, regarding the uptake as part of PCC.

- There were remarks considering the uptake of the following risk factors in PCC:

- Group B streptococcus (GBS). Due to the recurrence of GBS colonization after treatment, it is not considered beneficial to screen all women preconceptionally for GBS. However, PCC can identify women with previous GBS infection or neonatal complications due to GBS colonization. For these women, a management plan for their pregnancy and delivery can be formulated.

- HPV immunization. Although HPV carrier status is common, foetomaternal transmission rates and consequent neonatal outcomes are infrequent; there was consensus not to incorporate HPV carrier detection and immunization in PCC.

- Hepatitis B immunization. Where Hepatitis B infection is present in one of the future parents, routine clinical care was thought to be sufficient together with the local policy in pregnancy regarding vaccination of the neonate after birth. 
Table 1 Quality of the evidence for preconception risk factors and interventions to improve maternal and/or infant health and consensus on uptake in PCC

\begin{tabular}{|c|c|c|c|c|}
\hline Risk domain & Risk factors & Outcome & Intervention & Consensus \\
\hline \multirow[t]{3}{*}{ Health care promotion } & Interpregnancy intervals ( $<6$ months and $>60$ months) & II-2 & & + \\
\hline & Lack of physical exercise & II-2 & $\mathrm{I}-\mathrm{a}$ & + \\
\hline & Unplanned pregnancy & III & & + \\
\hline \multirow[t]{6}{*}{ Immunizations } & Human papilloma virus (HPV) & II-2 & & - \\
\hline & MMR & II-3 & II-2 & + \\
\hline & Hepatitis B & III & & - \\
\hline & Varicella & III & & + \\
\hline & Influenza & III & & - \\
\hline & DTP & III & & + \\
\hline \multirow[t]{15}{*}{ Infection } & Syphilis & $\mathrm{I}-\mathrm{a}$ & & + \\
\hline & HIV & $\mathrm{I}-\mathrm{b}$ & & + \\
\hline & Periodontal disease & $\mathrm{I}-\mathrm{b}$ & & + \\
\hline & Bacterial vaginosis & $\mathrm{I}-\mathrm{b}$ & & + \\
\hline & Asymptomatic bacteriuria & II-1 & $\mathrm{I}-\mathrm{a}$ & + \\
\hline & Herpes simplex virus (HSV) & II-1 & & + \\
\hline & Chlamydia & II-2 & & + \\
\hline & Toxoplasmosis & II-2 & & + \\
\hline & GBS & II-2 & & + \\
\hline & Tuberculosis & II-2 & & + \\
\hline & Hepatitis C & III & & + \\
\hline & Cytomegalovirus (CMV) & III & & + \\
\hline & Parvovirus & III & & + \\
\hline & Malaria & III & & + \\
\hline & Gonorrhoea & III & & + \\
\hline \multirow[t]{11}{*}{ Chronic medical conditions } & Diabetes mellitus type 1 or 2 & $\mathrm{I}-\mathrm{a}$ & $\mathrm{I}-\mathrm{a}$ & + \\
\hline & Thyroid disease & II-1 & & + \\
\hline & Phenylketonuria (PKU) & II-1 & & + \\
\hline & Seizure disorders & II-2 & & + \\
\hline & Hypertension & II-2 & & + \\
\hline & Systemic lupus erythematosus (SLE) & II-2 & & + \\
\hline & Chronic renal disease & II-2 & & + \\
\hline & Cardiovascular disease & II-2/II-3 & & + \\
\hline & Thrombophilia & II-3 & & + \\
\hline & Asthma & II-3 & & + \\
\hline & Rheumatoid arthritis (RA) & III & & + \\
\hline \multirow[t]{3}{*}{ Psychiatric conditions } & Depression and anxiety disorders & II-2 & & + \\
\hline & Bipolar disorder & II-2 & & + \\
\hline & Schizophrenia & II-2 & & + \\
\hline \multirow[t]{3}{*}{ Maternal exposure } & Alcohol & $\mathrm{I}-\mathrm{a}$ & $\mathrm{I}-\mathrm{a}$ & + \\
\hline & Tobacco & $\mathrm{I}-\mathrm{a}$ & & + \\
\hline & Illicit substances & II-2 & & + \\
\hline \multirow[t]{5}{*}{ Genetic risks } & Genetic disorder(s) or carriership in one of the prospective parents & II-2 & & + \\
\hline & Ethnicity-based risks & II-3 & & + \\
\hline & Positive family history & II-3 & & + \\
\hline & Recurrent miscarriages & III & II-2 & \\
\hline & Known genetic conditions & II-3 & & \\
\hline \multirow[t]{2}{*}{ Nutrition } & Inadequate folate intake & $\mathrm{I}-\mathrm{a}$ & $\mathrm{I}-\mathrm{a}$ & + \\
\hline & $\mathrm{BMI}>30 \mathrm{~kg} / \mathrm{m}^{2}$ & $\mathrm{I}-\mathrm{b}$ & $\mathrm{I}-\mathrm{a}$ & + \\
\hline
\end{tabular}


Table 1 (continued)

\begin{tabular}{|c|c|c|c|c|}
\hline Risk domain & Risk factors & Outcome & Intervention & Consensus \\
\hline & $\mathrm{BMI}<18 \mathrm{~kg} / \mathrm{m}^{2}$ & II-2 & & + \\
\hline & Insufficient vitamin $B_{12}$ & II-1 & & + \\
\hline & Inadequate dietary intake & II-2 & $\mathrm{I}-\mathrm{a}$ & + \\
\hline & Western dietary pattern & II-2 & & + \\
\hline & Excessive vitamin E intake & II-2 & & + \\
\hline & Insufficient vitamin D & II-3 & & + \\
\hline & Insufficient or excessive vitamin A intake & III & & + \\
\hline & Eating disorders & III & & + \\
\hline \multirow[t]{2}{*}{ Environmental exposures } & Occupational exposure (e.g. chemicals, solvents) & II-2 & & + \\
\hline & Household exposures (e.g. PCBs, solvents, metals (lead)) & III & & + \\
\hline \multirow[t]{2}{*}{ Psychosocial stressors } & Inadequate financial resources & II-2 & & + \\
\hline & Interpersonal violence & II-2 & & + \\
\hline \multirow[t]{3}{*}{ Medication } & Prescribed medication & II-1 & & + \\
\hline & Herbs/herbal products/weight loss products & II-1 & & + \\
\hline & Over-the-counter drugs & III & & + \\
\hline \multirow[t]{6}{*}{ Reproductive history } & Prior preterm birth & $\mathrm{I}-\mathrm{a}$ & & + \\
\hline & Prior miscarriage & $\mathrm{I}-\mathrm{a}$ & & + \\
\hline & Prior foetal growth restriction & II-2 & & + \\
\hline & Prior caesarean delivery & II-2 & & + \\
\hline & Prior stillbirth & II-2 & & + \\
\hline & Uterine anomalies & II-3 & & + \\
\hline \multirow[t]{3}{*}{ Special groups } & Immigrant and refugee populations & II-2 & & \\
\hline & Women who survived cancer & II-2 & & \\
\hline & Women with disabilities & III & & \\
\hline
\end{tabular}

Quality criteria: I-a, at least one properly conducted randomized controlled trial before pregnancy. I-b, at least one properly conducted randomized controlled trial not necessarily before pregnancy. II-1, well-designed controlled trials without randomization. II-2, cohort or case-control studies. II-3, multiple time series with or without intervention or dramatic results in uncontrolled experiments. III, opinions on clinical experience, descriptive statistics, case reports or reports of experts committees

- Although the review did not point out the following risk factors, the experts noted the following risk factors to be taken up as part of PCC:

- Chronic medical conditions such as inflammatory bowel disease (colitis, Crohn's disease), women with organ transplants, previous thrombotic event or embolism.

- Genetic risks such as consanguinity.

- Exposures such as occupational exposure to working shifts and stress, sauna, diving and passive smoking as part of household exposure.

- Psychosocial stressors such as adverse childhood events

- Reproductive history such as subfertility, prior pregnancy complications, prior congenital anomalies, prior neonatal complications and advanced maternal age (defined as older than 36 years).

- Prospective parents may have questions (e.g. with regard to fertility and sexual health). PCC providers should assess needs and inform or refer where necessary parallel to their risk assessment.

- The current proposal focuses on individual risk factors. The participants agreed that the effect of risk accumulation should be recognized. Risk accumulation is the phenomenon that combinations of risk factors augment the total risk of the individual to a larger extent than the sum of the individual risks (Timmermans et al. 2011).

\section{Knowledge gaps/recommended future research}

- More research is needed regarding the population attributable risks (PAR) of preconception risk factors and combined effects of risk factors.

- A remark can be made by the risk factor 'unplanned pregnancy'. It is unclear whether this considers unplanned pregnancies that are welcome or not welcome. This might 
be an important factor affecting pregnancy outcome as risky behaviour is more likely to happen when a pregnancy is unwanted. More insight is necessary in the contributory risk component in unplanned pregnancy: unwantedness versus the unplanned nature.

- As the possible content of PCC is growing, there is a need for prioritization in the interventions for a woman's specific risk profile. There is no method to identify the best core of action, and a fixed format is not feasible due to interindividual differences. PCC providers are subjected to 'common sense' in the prioritization of risk factors. This should be based on the impact of risk factors and the feasibility of interventions.

Risk assessment instruments

\section{Introduction}

Assessing preconception risk factors within all domains is time consuming and to stimulate a uniform risk assessment, risk assessment instruments are necessary.

Available risk assessment instruments were identified:

- ZwangerWijzer (www.zwangerwijzer.nl) is the most widely used instrument in the Netherlands (Landkroon et al. 2010). It is a validated tool based on the preconception health assessment form developed by Cefalo and Moos (Cefalo and Moos 1995). It is a selfadministered online questionnaire that assesses and informs about medical, genetic, environmental, occupational, nutritional and lifestyle risk factors. The identified risks can be emailed to a caregiver - to provide an agenda for individual PCC. A supportive programme provides the caregiver with a preconception patient record with protocols to address each identified risk factor (www. Preconceptiewijzer.nl).

- SlimmerZwanger (www.slimmerzwanger.nl) is a personal screening and coaching programme provided by mobile phone app. The application assesses nutrition and lifestyle behaviours by a self-administered questionnaire. The application then provides motivational text messages and email messages to change risky behaviours. Effectiveness is currently being assessed.

\section{Proposition}

- The proposition is to include generic risk assessment instruments suitable for the local setting in PCC.

\section{Consensus}

- Instruments with a wide range of detecting risk factors to limit the amount of questionnaires are preferable.

- Risk assessment instruments can lead to awareness and therefore can function as an intervention themselves.

\section{Knowledge gaps/recommended future research}

- Appropriate evidence-based standardized risk assessment instruments remain to be developed or existing tools should be optimized (e.g. multilingual) and validated.

\section{Summary}

In conclusion, a consensus was achieved on the majority of the key elements of PCC, including the definition, the categorisation, institutes and health care professionals which should play a role in reaching target groups, the content and delivery and the need for development of evidence-based risk assessment instruments. These elements give further insight in what should be resolved in order to enlarge the scale at which PCC is delivered. Furthermore, these can be used as starting points for policymakers and other relevant actors that take responsibility to develop implementation strategies for PCC.

In order to develop a tailored PCC programme, the needs of specific populations should be known and resources should be in line with setting specific characteristics.

This consensus paper is based on current evidence. Biannual update on the evidence of preconception risk factors and management is recommended to keep the debate going. This debate is necessary to hold the commitment amongst the broad scope of professionals in the curative setting and the public health care setting to collaborate regarding PCC.

Acknowledgments The Erasmus MC group is grateful to the following participants (in alphabetical order): I. Aalhuizen, Royal Dutch Organization of Midwives (KNOV), Utrecht; A. Annegarn, Regional Organisational Support for Primary health care (ROS), Amsterdam; R. Bakker, Erasmus University Medical Center, Rotterdam; M. Beentjes, Royal Dutch Organization of Midwives (KNOV), Utrecht; M. Breden, Netherlands Organisation for Health Research and Development (Zon MW), The Hague; G.J. Bonsel, Erasmus University Medical Center, Rotterdam; T. Brand, VU University Medical Center, Amsterdam; M.C. Cornel, VU University Medical Center, Amsterdam (chair); M.R. Crone, Leiden University Medical Center, Leiden; J. Derksen, the Health Care Insurance Board, Diemen; S.B. Detmar, Organisation for Applied Scientific Research (TNO), Child Health, Leiden; J. Dijs-Elsinga, Perinatal Registry Netherlands (PRN), Utrecht; K. Dolsma, Dutch National Genetic Resource and Information Center (Erfocentrum), Woerden; C. Hoving, Maastricht University Medical Center, Maastricht; A.A.J. van Iersel, Ministry of Health Welfare and Sport, The Hague; S. Jans, Royal Dutch 
Organization of Midwives (KNOV), Utrecht; A.H.J. Jaspar, National Association of General Practitioners (NHG), Utrecht; L.P. ten Kate, Leiden University Medical Center, Leiden, Foundation of Preconception Care, Soest; C. Kirpestein, IRIS, Tiel; A. Kruger-Adriaenssen, Agis, Amersfoort; P. Lakeman, VU University Medical Center, Amsterdam; R. Lamara, Dutch National Genetic Resource and Information Center (Erfocentrum), Woerden; A. Meeuwese, National Institute for Public Health and the Environment (RIVM), Bilthoven; C. Oosterwijk, Dutch Genetic Alliance of Parent and Patient organizations (VSOP), Soest; K. van der Pal- de Bruin, Organisation for Applied Scientific Research (TNO), Child Health, Leiden; M. Prins, Ministry of Health Welfare and Sport, The Hague; S Rombout- de Weerd, Albert Schweitzer Hospital, Dordrecht (chair); M. Rooseboom, Netherlands Organisation for Health Research and Development (Zon MW), The Hague; V.W.T. Ruiz- van Haperen, Health Council of the Netherlands (Gezondheidsraad), The Hague; K. Scheele, CZ, Tilburg; D.J. de Smit, MediClara Projects BV, Abcoude; R.P.M. Steegers-Theunissen, Erasmus University Medical Center, Rotterdam; S. Veen, Leiden University Medical Center, Leiden; P. Verloove- van Hoorick, Leiden University Medical Center, Leiden; M. Vesters, Netherlands Organisation for Health Research and Development (Zon MW), The Hague; E.A.P. van Vliet-Lachotzki, Dutch National Genetic Resource and Information Center (Erfocentrum), Woerden; A.J.J. Voorham, Municipality of Rotterdam (GGD RotterdamRijnmond), University of Applied Sciences of Rotterdam, Rotterdam; A.J. Waarlo, University Medical Center Utrecht, Utrecht; G. de Wert, Maastricht University Medical Center, Maastricht; S. Westerik, Regional Organisational Support for Primary health care (ROS), Friesland; B. Wijsen, Commission for Perinatal Health (CPZ), Utrecht; the Netherlands.

Compliance with ethics guidelines This article does not contain any studies with human or animal subjects performed by any of the authors.

Sevilay Temel, Sabine van Voorst, Lieke de Jong- Potjer, Adja Waelput, Martina Cornel, Sabina Rombout- de Weerd, Semiha Denktaş, Eric Steegers declare that they have no conflict of interest.

\section{References}

Bonsel GJ, Birnie E, Denktas S, Poeran J, Steegers EAP (2010) Signalementstudie 'Zwangerschap en geboorte'. Lijnen in de perinatale sterfte [in Dutch]. Rotterdam

Cefalo RC, Moos MK (1995) Preconceptional health care: a practical guide. Mosby-Year Book, St. Louis

Delvoye P, Guillaume C, Collard S, Nardella T, Hannecart V, Mauroy MC (2009) Preconception health promotion: analysis of means and constraints. Eur J Contracept Reprod Health Care 14:307-316. doi: $10.1080 / 13625180903056123$

Denktas S et al. (2011) An urban perinatal health programme of strategies to improve perinatal health. Matern Child Health J doi:10.1007/ s10995-011-0873-y

Elsinga J, van der Pal-de Bruin K, le Cessie S, de Jong-Potjer L, Verloove-Vanhorick S, Assendelft W (2006) Preconception counselling initiated by general practitioners in the Netherlands: reaching couples contemplating pregnancy [ISRCTN53942912]. BMC Fam Pract 7:41. doi:10.1186/1471-2296-7-41

Frey KA, Navarro SM, Kotelchuck ML, M. C. (2008) The clinical content of preconception care: preconception care for men Am J
Obstet Gynecol 199:S389-395 doi:S0002-9378(08)02037-1 [pii]10.1016/j.ajog.2008.10.024

Gage JD, Everett KD, Bullock L (2007) A review of research literature addressing male partners and smoking during pregnancy. J Obstet Gynecol Neonatal Nurs 36:574-580. doi:10.1111/j.1552-6909. 2007.00188

Gaytant MA, Cikot RJ, Braspenning JC, Grol RP, Merkus JM, Steegers EA (1998) [Preconception counseling in family practice: a survey of 100 family physicians] Preconceptionele advisering in de huisartspraktijk; een enquete onder 100 huisartsen. Ned Tijdschr Geneeskd 142:1206-1210

Jack BW, Atrash H, Coonrod DV, Moos MK, O’Donnell J, Johnson K (2008) The clinical content of preconception care: an overview and preparation of this supplement. Am J Obstet Gynecol 199:S266S279. doi:10.1016/j.ajog.2008.07.067

Janz NK et al (1995) Diabetes and pregnancy. Factors associated with seeking pre-conception care. Diabetes Care 18:157-165

Korenbrot CC, Steinberg A, Bender C, Newberry S (2002) Preconception care: a systematic review. Matern Child Health J 6: $75-88$

Landkroon AP, de Weerd S, van Vliet-Lachotzki E, Steegers EAP (2010) Validation of an internet questionnaire for risk assessment in preconception care. Public Health Genomics 13(2): 89-94

Owens MD, Kieffer EC, Chowdhury FM (2006) Preconception care and women with or at risk for diabetes: implications for community intervention. Matern Child Health J 10:S137-S141. doi:10.1007/ s10995-006-0098-7

Posner SF, Johnson K, Parker C, Atrash H, Biermann J (2006) The national summit on preconception care: a summary of concepts and recommendations. Matern Child Health J 10:S197-S205. doi: 10.1007/s10995-006-0107-x

Posthumus AG et al (2012) Bridging between professionals in perinatal care: towards shared care in The Netherlands. Matern Child Health J. doi:10.1007/s10995-012-1207-4

Pubmed MeSH Database (1992) http://www.ncbi.nlm.nih.gov/mesh/? term $=$ care $\% 2 \mathrm{C}+$ preconception

Sternberg P, Hubley J (2004) Evaluating men's involvement as a strategy in sexual and reproductive health promotion. Health Promot Int 19: 389-396. doi:10.1093/heapro/dah31219/3/389

Temel S, van Voorst SF, Jack BW, Denktas S, Steegers EA (2014) Evidence-based preconceptional lifestyle interventions. Epidemiol Rev 36:19-30. doi:10.1093/epirev/mxt003

Timmermans $S$ et al (2011) Individual accumulation of heterogeneous risks explains perinatal inequalities within deprived neighbourhoods. Eur J Epidemiol 26:165-180. doi:10.1007/ s10654-010-9542-5

US Preventive Services Task Force (1996) Guide to clinical preventive services. Williams and Wilkins, Baltimore

van der Zee B, de Beaufort I, Temel S, de Wert G, Denktas S, Steegers E (2011) Preconception care: an essential preventive strategy to improve children's and women's health. J Public Health Policy 32: 367-379. doi:10.1057/jphp.2011.13

Williams JL, Abelman SM, Fassett EM, Stone CE, Petrini JR, Damus K, Mulinare J (2006) (2006) Health care provider knowledge and practices regarding folic acid, United States. Matern Child Health J 10:S67-S72. doi:10.1007/s10995-006-0088-9

The Health Council of the Netherlands (2007) Preconception care: a good beginning. The Hague: Health Council of the Netherlands 